\title{
Criação de uma interface gráfica de um incêndio florestal
}

\author{
Silveira, B. S. ${ }^{1^{*}}$; Da Silva, W. B. ${ }^{2}$; Alves, K. S. ${ }^{3}$ \\ 1 Curso de Graduação em Engenharia Química, Universidade Federal do Espírito Santo, Alegre, ES, Brasil. \\ 2 Pós-Graduação em Engenharia Química e Graduação em Engenharia Química, Departamento de Engenharia Rural, \\ Universidade Federal do Espirito Santo, ES, Brasil. \\ 3 Curso de Graduação em Agronomia, Universidade Federal do Espírito Santo, Alegre, ES, Brasil. \\ *e-mail: bryan.ss@yahoo.com
}

\begin{abstract}
Resumo
Os impactos ambientais causados pelos incêndios florestais afetam a dinâmica bioclimática do planeta ao alterar seus ciclos e destruir seus ecossistemas, além de estar diretamente ligada a segurança pública. Dessa maneira, são necessárias medidas de ação de combate a esses danos ambientais. A criação de uma interface gráfica utilizando a modelagem e simulação de incêndios é uma medida importante para auxiliar nessa problemática, através, por exemplo, da previsão da direção de propagação de um incêndio. As interfaces gráficas facilitam a interação entre usuário e a máquina. Este trabalho tem como objetivo a criação de uma interface gráfica de um incêndio florestal. As simulações foram feitas para incêndios com três tipos de vegetação e dois tipos de foco de incêndio.
\end{abstract}

\begin{abstract}
The environmental impacts caused by forest fires affect the bioclimatic dynamics of the planet to change their cycles and destroy their ecosystems, as well as being directly linked to public safety. In this way, are necessary courses of action to combat this environmental damage. Creating a GUI using the modeling and simulation of fires is an important measure to assist with this problem by, for example, the prediction of the direction of propagation of a fire. Graphical interfaces facilitate interaction between user and machine. This work aims to create a graphical interface of a forest fire. The simulations were made for fire with three kinds of vegetation and two types of the fire.
\end{abstract}

Keywords (Palavras chaves): simulação computacional, interface gráfica, incêndio florestal.

\section{Introdução}

Os incêndios florestais causam inúmeros danos e perdas irreparáveis do ponto de vista ecológico e econômico, gerando grandes preocupações a sociedade devido à emissão de carbono na atmosfera. Dessa forma, a rapidez e a eficiência na detecção e monitoramento dos incêndios são de fundamental importância para a viabilização do controle do fogo, redução dos custos nas operações de combate e atenuação dos danos. A determinação de áreas de risco pode ser útil para a atuação do corpo de bombeiros [1].

O incêndio acontece quando ocorre a quando a celulose, presente na vegetação, reage com gás oxigênio presente no ar com a presença de uma fonte de calor. O combustível para a ocorrência desse fenômeno, a vegetação, é responsável por conduzir a propagação do fogo. A região da vegetação que há intensa combustão, com grande quantidade de calor sendo produzida, é denominada frente de fogo. A região de aquecimento é a região do combustível vegetal próxima à frente de fogo e que sofre pirólise ocasionada pela ação do calor emitido pela frente de fogo [2].

O comportamento do fogo em incêndios de vegetação é influenciado pelo tipo de vegetação, as condições climáticas e a topografia. A vegetação é a fonte de energia para o processo e é caracterizada em termos de arranjo e teor de umidade. A umidade relativa, temperatura do ar, velocidade do vento, precipitação são fatores que caracterizam as condições atmosféricas e influenciam na velocidade e direção de propagação do fogo e no teor de umidade da 


\section{SEMANA DE ENGENHARIA QUÍMICA UFES}

Blucher

vegetação. Dentre os fatores relacionados com as condições atmosféricas, a vento tem relativa importância em conduzir uma tendência na direção de propagação da frente de fogo. A topografia também influencia diretamente a velocidade e a direção de propagação da frente de fogo, pois o fogo se propaga mais rapidamente em superfícies com elevação, quando comparadas a superfícies planas [2].

Com a necessidade de conhecer e controlar esse fenômeno surgiu à modelagem da propagação do fogo em incêndios de vegetação. O objetivo é descrever e modelar os mecanismos relacionados à propagação do fogo sobre a vegetação em função dos fatores que a condicionam [2].

A necessidade de apoiar os estudos de estratégias, controle e combate a incêndios, faz com que seja importante o desenvolvimento de uma ferramenta computacional para 0 auxilio dessa tarefa. A implementação de modelos matemáticos baseados em fenômenos físicos, como os incêndios florestais, vem sendo realizados com frequência. Além disso, a complexidade envolvida no processo e na estimação dos parâmetros de incêndios incentiva a utilização de modelos físicos para simular tais processos. Dessa forma, ao utilizar a experiência de campo com as simulações computacionais com o objetivo de se prevenir contra incêndios ou decidir, por exemplo, onde e quando uma ação de combate a incêndios deve ser iniciada ou que extensão de dano um foco de incêndio pode atingir depois de certo tempo de evolução do fogo [3].

Os resultados obtidos através de simulações computacionais podem ser de difícil interpretação. Dessa forma, se os usuários dos programas computacionais não forem envolvidos no desenvolvimento do mesmo, são criados sistemas inúteis, fazendo com que seja importante a criação de uma interface gráfica. Em uma interface gráfica, o utilizador valoriza a facilidade com que consegue executar as tarefas pretendidas e a comodidade ao executá-las [4].

O objetivo deste trabalho é a criação de uma interface gráfica que descreve a propagação de um incêndio florestal.

\section{Materiais e Métodos}

Para a criação da interface gráfica, é necessário que sejam feitas simulações utilizando um modelo matemático que represente o fenômeno físico de estudo deste trabalho. O modelo de propagação do incêndio utilizado foi baseado nos fenômenos de transferência de calor e massa, e na termodinâmica desenvolvido por ROCHOUX (2010). Inicialmente, foram feitas simulações utilizando o modelo de propagação de incêndio unidimensional, e posteriormente para o caso bidimensional. Para o caso bidimensional, foram testadas diversas condições de ocorrência do incêndio. A condição inicial era determinada pelo tipo de foco de incêndio, neste trabalho foram considerados os focos de fogo linear e circular. Além disso, foi considerado também qual o tipo de vegetação que ocorria o incêndio, isso influencia na velocidade e direção de propagação da chama (o tipo de vegetação determina o valor de alguns parâmetros do modelo). Foram simulados modelos para o caso de vegetação isotrópica (vegetação distribuída uniformemente no espaço), linear (quantidade de vegetação aumenta linearmente em uma direção) e randômica (quantidade de vegetação é aleatória no espaço). As simulações numéricas foram feitas utilizando o método das linhas para o caso unidimensional e o método de diferenças finitas para o caso bidimensional. Foi utilizado o software MATLAB na resolução desse problema. A ferramenta ode45 auxiliou na solução do caso unidimensional. As equações dos modelos e parâmetros são descritas abaixo. Os valores dos parâmetros utilizados na simulação foram obtidos em [5].

O modelo da propagação do incêndio unidimensional é dado pela equação 1 .

$$
\frac{\partial c}{\partial t}=D \frac{\partial^{2} c}{\partial x^{2}}+a(1-c)
$$

em que:

$$
\begin{gathered}
D=s_{L, K P P} \delta_{L, K P P} \\
a=\frac{s_{L, K P P}}{4 \delta_{L, K P P}}
\end{gathered}
$$

O termo $\mathrm{s}_{\mathrm{L}, \mathrm{KPP}}$ é a velocidade da chama (termo que recebe influencia do tipo de vegetação) e $\delta_{L, K P P}$ é a espessura da chama. A condição inicial para esse caso é dada pela equação 4 . 


\section{SEMANA DE ENGENHARIA QUÍMICA UFES}

Blucher

$$
c(x)=\frac{\exp (x-150)}{\exp (x-150)+0,9}
$$

O modelo bidimensional da propagação de incêndio é dado pela equação 5 .

$$
\frac{\partial c}{\partial t}=\left(\frac{\beta \delta s_{L}}{2}\right) \nabla c+\left(\frac{s_{L}}{2 \beta \delta}\right) c(1-c)
$$

em que $\beta$ é um parâmetro numérico.

Para o caso bidimensional, as condições iniciais para o caso de foco de incêndio com fogo linear e circular são, respectivamente, dadas pelas equações 6 e 7 .

$$
\begin{gathered}
c(x, y)=\frac{\exp (x-150)}{\exp (x-150)+0,9} \\
c(x, y)=0,5\left(1-\tanh \left(2\left(\frac{r(x, y)}{5}-\frac{5}{r(x, y)}\right)\right)\right) \\
r(x, y)=\sqrt{(x-100)^{2}+(y-100)^{2}}
\end{gathered}
$$

A etapa de simulação consiste em resolver as equações diferenciais apresentadas acima para que se possa descrever como ocorre a propagação de um incêndio em diversas situações. Visto que os resultados obtidos nas simulações eram satisfatórios, foi desenvolvida a interface gráfica utilizando os códigos das mesmas. Isso foi feito utilizando a ferramenta GUIDE presente no MATLAB. A interface foi criada para fornecer ao usuário como o incêndio se propagou em uma região bidimensional após um instante de tempo determinado pelo usuário, e pelo tipo de vegetação e fogo, também determinados pelo usuário.

\section{Resultados e Discussões}

Os resultados obtidos na simulação foram similares aos que Silva (2012) obteve, dessa forma, pode-se dizer que as ferramentas utilizadas para solucionar as equações diferencias são uma boa escolha. $\mathrm{Na}$ interface gráfica criada, é necessário que o usuário selecione qual o tipo de foco de incêndio, linear(linf) ou circular (circ), o tipo de vegetação, isotrópica (iso), linear (linv) ou randômica (rand). Além disso, o usuário deve digitar em qual instante de tempo (em segundos) ele deseja saber como estará o incêndio. Ao clicar em iniciar, o programa gera uma imagem com o resultado da simulação. A figura 1 mostra como é a interface gráfica.

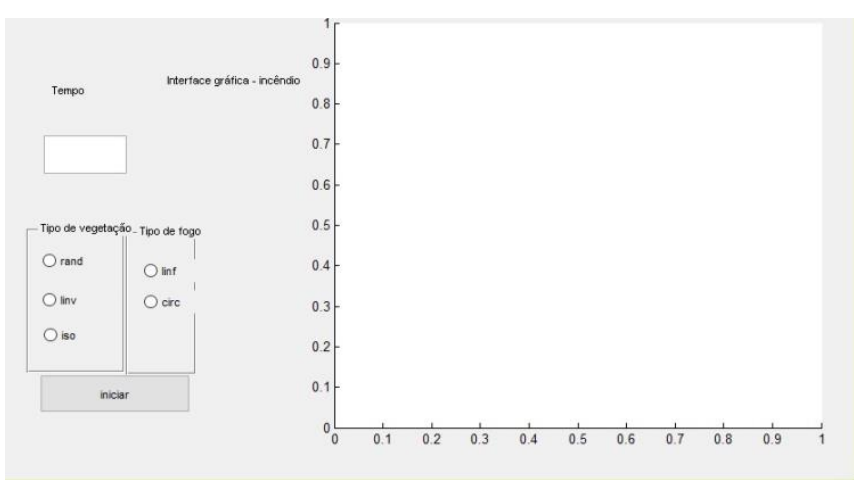

Figura 1: Área de trabalho da interface gráfica.

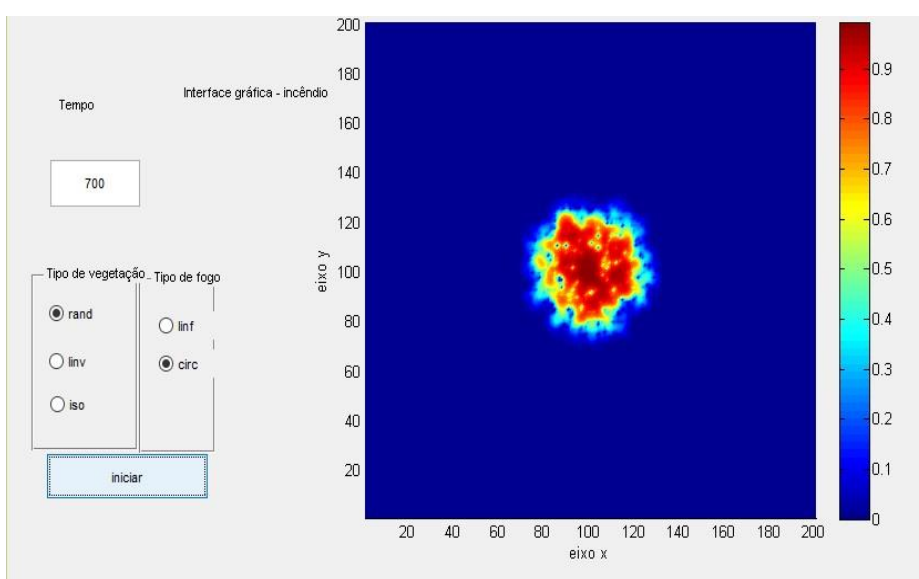

Figura 2: Exemplo de um resultado obtido ao utilizar a interface gráfica.

A figura 2 mostra os resultados obtidos para a simulação após 700 segundos para o tipo de vegetação randômica e foco de incêndio circular.

\section{Conclusões}

A partir do resultado apresentado nesse trabalho, podese concluir que o desenvolvimento de interfaces gráficas para auxiliar na simulação de fenômenos físicos, já que isso auxilia o usuário na solução de seu problema. Nesse trabalho, não considerou-se que a velocidade da frente da chama (região em que $c$ vale $0,5)$ variava ao longo do tempo. Propõe-se para trabalhos futuros a implementação do código que faça o cálculo desse parâmetro ao longo do tempo e através disso, espera-se que seja obtido uma simulação mais realística desse fenômeno. Além disso, propõe-se também para gerar melhores resultados nas simulações a utilização de imagens de satélites. 


\section{Referências Bibliográficas}

[1] OLIVEIRA, A. L. S. Modelagem Espacial de Riscos de Incêndios com Lógica Fuzzy, Comparação e Validação. Dissertação (Mestrado em Ciências Geodésicas e Tecnologias da Geoinformação), Programa de Pós-Graduação em Ciências Geodésicas e Tecnologias da Geoinformação, Universidade Federal de Pernambuco, Recife, 2013.

[2] ALMEIDA, R. M. Modelagem da Propagação do Fogo como Ferramenta de Auxílio à Tomada de Decisão no Combate e Prevenção de Incêndios no Parque Nacional das Emas, GO. Tese (Doutorado em Computação Aplicada), Programa de Pós-Graduação em Computação Aplicada, Instituto Nacional de Pesquisas Espaciais, São José dos Campos, 2012.

[3] SILVA Jr., D. B. Modelagem Computacional de Incêndios e Queimadas: Um Estudo de Caso sobre a Reserva Biológica do Lago Piratuba-AP. Dissertação
(Mestrado em Desenvolvimento de Processos Ambientais), Programa de Pós-Graduação em Desenvolvimento de Processos Ambientais, Universidade Católica de Pernambuco, Recife, 2007.

[4] GONÇALVES, P. C. T. Desenvolvimento de uma Interface Gráfica para o Programa FastComp. Dissertação (Mestrado em Métodos Computacionais em Ciências e Engenharias), Faculdade de Ciências e Engenharia da Universidade do Porto, Universidade do Porto, Porto, 2009.

[5] SILVA, W. B.; ORLANDE, H. R. B.; COLAÇO, M. J.; FUDYM, O.; EL HAFI, Mouna; CUENOT Bénedicte; ROCHOUX Mélanie. Application des filtres de particules à l'estimation de la vitesse de propagation d?incendies. In: Congrés Français de Thermique, 2012, Bordeaux. Congrés Français de Thermique, 2012. 